\title{
CONCENTRATION-COMPACTNESS PRINCIPLE FOR EMBEDDING INTO MULTIPLE EXPONENTIAL SPACES
}

\author{
ROBERT ČERNÝ
}

Abstract. Let $\Omega \subset \mathbb{R}^{n}, n \geqslant 2$, be a bounded domain and let $\alpha<n-1$. We prove the ConcentrationCompactness Principle for the embedding of the Orlicz-Sobolev space $W_{0}^{1} L^{n} \log ^{n-1} L \log ^{\alpha} \log L(\Omega)$ into the Orlicz space corresponding to a Young function that behaves like $\exp \left(\exp \left(t^{\frac{n}{n-1-\alpha}}\right)\right)$ for large $t$. We also give the result for the case of the embedding into triple and other multiple exponential spaces.

Mathematics subject classification (2010): 46E35, 46E30, 49J99.

Keywords and phrases: Orlicz spaces, Orlicz-Sobolev spaces, embedding theorems, sharp constants, concentration-compactness principle.

\section{REFERENCES}

[1] L. Carleson, S.-Y. A. Chang, On the existence of an extremal function for an inequality of J. Moser, Bull. Sci. Math. (2), 110, 2 (1986), 113-127.

[2] R. ČERNÝ, P. GURKA, S. HENCL, Concentration-compactness principle for generalized Trudinger inequalities, submitted (preprint is available at www.karlin.mff.cuni.cz/kma-preprints/).

[3] R. ČERNÝ, S. MAŠKOVÁ, A sharp form of an embedding into multiple exponential spaces, Czechoslovak Math. J., 60, 3 (2010), 751-782.

[4] R. ČERNÝ, S. MAŠKOVÁ, On generalization of Moser's theorem in the critical case, Math. Inequal. Appl., 13, 4 (2010), 785-802.

[5] A. Cianchi, A sharp embedding theorem for Orlicz-Sobolev spaces, Indiana Univ. Math. J., 45 (1996), 39-65.

[6] D.E. Edmunds, P. GuRKA, B. OpIC, Double exponential integrability of convolution operators in generalized Lorentz-Zygmund spaces, Indiana Univ. Math. J., 44 (1995), 19-43.

[7] D.E. Edmunds, P. Gurka, B. OpIC, Double exponential integrability, Bessel potentials and embedding theorems, Studia Math., 115 (1995), 151-181.

[8] D.E. Edmunds, P. GuRKA, B. OpIC, Sharpness of embeddings in logarithmic Bessel-potential spaces, Proc. Roy. Soc. Edinburgh, 126A (1996), 995-1009.

[9] D.E. Edmunds, P. Gurka, B. OpIC, On embeddings of logarithmic Bessel potential spaces, J. Functional Analysis, 146 (1997), 116-150.

[10] D.E. Edmunds, P. Gurka, B. OPIC, Norms of embeddings in logarithmic Bessel-potential spaces, Proc. Amer. Math. Soc., 126 (1998), 2417-2425.

[11] D.G. Figueiredo, O. H. Miyagaki, B. Ruf, Elliptic equations in $\mathbb{R}^{2}$ with nonlinearities in the critical growth range, Calc. Var., 3 (1995), 139-153.

[12] D.G. DE Figueiredo, J. Marcos Do Ó, B. RuF, On an Inequality by N.Trudinger and J.Moser and Related Elliptic Equations, Comm. Pure Appl. Math., 55 (2002), 135-152.

[13] D.E. Edmunds, M. Krbec, Two limiting cases of Sobolev imbeddings, Houston J. Math., 21 (1995), 119-128.

[14] N. Fusco, P. L. Lions, C. Sbordone, Sobolev imbedding theorems in borderline cases, Proc. Amer. Math. Soc., 124 (1996), 561-565.

[15] L. I. Hedberg, On certain convolution inequalities, Proc. Amer. Math. Soc., 36 (1972), 505-512.

[16] S. HENCL, A sharp form of an embedding into exponential and double exponential spaces, J. Funct. Anal., 204 (2003), 196-227. 
[17] P. L. LiOns, The concentration-compactness principle in the calculus of variations. The limit case. I., Rev. Mat. Iberoamericana, 1, 1 (1985), 145-201.

[18] J. Moser, A sharp form of an inequality by N. Trudinger, Indiana Univ. Math. J., 20 (1971), 10771092.

[19] J. MARCos Do Ó, Semilinear Dirichlet problems for the $N$-laplacian in $\mathbb{R}^{n}$ with nonlinearities in the critical growth range, Differential Integral Equations, 9, 5 (1996), 967-979.

[20] B. OpIC, L. PICK, On generalized Lorentz-Zygmund spaces, Math. Inequal. Appl., 2 (July 1999), 391-467.

[21] M. M. RaO, Z. D. REN, Theory of Orlicz spaces, Pure and applied mathematics, 1991.

[22] R. S. Strichartz, A note on Trudinger's extension of Sobolev's inequality, Indiana Univ. Math. J., 21 (1972), 841-842.

[23] G. TALENTI, Inequalities in rearrangement invariant function spaces, Nonlinear Analysis, Function Spaces and Applications 5, Prometheus Publ. House Prague, 1994, 177-230.

[24] K. Tintarev, K. H. Fieseler, Concentration compactness, Imperial College Press, London, 2007.

[25] N. S. Trudinger, On imbeddings into Orlicz spaces and some applications, J. Math. Mech., 17 (1967), 473-484.

[26] V. I. Yudovich, Some estimates connected with integral operators and with solutions of elliptic equations, Soviet Math. Doklady, 2 (1961), 746-749. 